Archivum, LXXI, 2021, pp. 151-182

\title{
Los poemas helénicos inéditos de Fabriciano González ${ }^{1}$
}

\author{
Ramiro González Delgado \\ UNIVERSIDAD DE EXTREMADURA \\ rgondel@unex.es
}

Recibido: 11/01/2021

Aceptado: 14/05/2021

\begin{abstract}
RESUMEN:
Tras el descubrimiento de dos manuscritos de Fabriciano González "Fabricio" en el archivo de Enrique García Rendueles (depositado en la Biblioteca de Asturias), editamos estos dos poemas ("A la muerte de Adonis" y "La rueca") y analizamos las traducciones de Teócrito hechas por este autor asturiano, deudoras de las realizadas por Félix Aramburu Zuloaga (en lengua asturiana) y por Ignacio Montes de Oca (en castellano).
\end{abstract}

PALABRAS CLAVE: Poesía en lengua asturiana, Bucólica griega, Traducción, Tradición clásica, plagio, comienzos del siglo XX.

1 Este trabajo se ha realizado en el marco del proyecto de investigación Portal digital de Historia de la Traducción en España, PGC2018-095447-B-I00 (MCIU/AEI/FEDER, UE). También se adscribe al grupo de investigación LAPAR (HUM002), financiado por fondos FEDER, del plan I+D+I de Extremadura. 
Hellenic unpublished poems by Fabriciano González

\begin{abstract}
:
After the discovery of two manuscripts by Fabriciano González "Fabricio" in the archive of Enrique García Rendueles (deposited in the Library of Asturias), we edit these two poems ("The Dead Adonis" and "The distaff") and analyze the translations from Theocritus by this Asturian author, plagiarism of those made by Félix Aramburu Zuloaga (translated into Asturian language) and by Ignacio Montes de Oca (into Spanish).
\end{abstract}

KEYWORDS: Poetry in Asturian Language, Ancient Greek Pastoral Poetry, Translation, Classical Tradition, Plagiarism, early $20^{\text {th }}$ Century.

\title{
1. Introducción
}

En el fondo Enrique García Rendueles de la Biblioteca de Asturias "Ramón Pérez de Ayala" (Oviedo) aparecieron dos manuscritos, ambos firmados con el nombre de Fabricio, que contienen dos poemas titulados "La Rueca (sobre motivos del idilio XXVIII de Teócrito) y "A la muerte de Adonis (versión al bable del Idilio XXX de Teócrito)". Desde aquí, quiero agradecer a Juan Miguel Menéndez Llana, director de dicha Biblioteca, el encuentro de estas pequeñas joyas entre los papeles de García Rendueles y, especialmente, que me haya informado del hallazgo y facilitado una copia de los manuscritos para su estudio. Estos dos poemas se suman a otro ya conocido de Fabriciano González, "El ladronzuelo de panales (Idilio XIX de Teócrito)", una rara avis en su producción poética, netamente costumbrista. Así, en este trabajo vamos a situar al autor en su contexto, para entender mejor esta atípica producción literaria, editaremos los textos manuscritos descubiertos y analizaremos estos poemas, que son traducciones de idilios atribuidos a Teócrito.

\section{2.. Fabriciano González, Fabricio}

Fabriciano González García (1868-1950) fue un hombre culto que defendió durante toda su vida la cultura popular asturiana. Licenciado en Derecho por la Universidad de Oviedo, ejer- 
ció como maestro de enseñanza primaria, fue redactor jefe del periódico El Comercio, abogado, secretario del Ayuntamiento de Laviana (hasta que se jubila), cronista oficial de Gijón y un incansable escritor de poesías, cuentos, artículos periodísticos y piezas de teatro. Fue un hombre hecho a sí mismo, que promovió la autonomía asturiana fundando la revista El Regionalista Astur (1919; Fabricio, 2001c) y la creación de la Real Academia Asturiana de Artes y Letras ${ }^{2}$. Defensor de la lengua asturiana, tanto en la teoría como en la práctica, escribió cientos de poemas, repartidos en publicaciones periódicas de España e Hispanoamérica, obras de teatro (y textos de zarzuelas) que se representaron (pero no se publicaron) y varios cuentos (Rosina fue premiado en el concurso literario de Oviedo en el año 1941). En formato libro, tan solo publicó en vida este cuento citado (Fabricio, 1943) y, en 1925, una colección de poemas, Munchu güeyu cola xente de casa (cien sonetos donde el autor realiza una prosopopeya de diferentes personajes de su época, incluyéndose a sí mismo), acompañada del monólogo Un alcalde de montera (Fabricio, 1925). Años más tarde, Luciano Castañón preparó una antología de sus textos, donde incluye algunos de los sonetos de Munchu gueyu..., pero rescató también varias colaboraciones que publicó en prensa (Fabricio, 1987). Esta antología es bastante deficitaria al no indicar fechas ni origen de los textos (en qué periódico o revista se publicaron, si se encontraron manuscritos...). Publicaciones posteriores rescatan poemas suyos que habían aparecido en las efímeras páginas de periódicos o revistas (Campal, 1997; Fabricio, 1999a y 2003; González Delgado, 2000, 47), cuentos (García, 1992, 43-47), artículos periodísticos (Fabricio, 2001b)33 , obra manuscrita (Fabricio, 2001a) -poemas como "La batalla de Covadonga" y cartas-, además de una nueva edición de su emblemática obra (Fabricio, 1999b), esta vez sin el monólogo, y otra edición facsimilar completa de la misma (Fabricio, 2010). Por todo ello, es necesario hacer una edición

2 Para una biografía del autor, véase Castañón (1987, 7-37).

3 Contiene los publicados en la revista Paz social, entre el 12 de octubre de 1924 y el 16 de marzo de 1931. 
de sus obras completas, tanto publicadas en prensa como manuscritas, que abarque todos los géneros que cultivó (poesía, prosa y teatro) y también las lenguas que empleó (principalmente la asturiana, pero también la castellana). La temática costumbrista es la mayoritaria en sus composiciones, pues no en vano es uno de los principales representantes del Rexonalismu asturiano.

A comienzos del siglo XX (y hasta la guerra civil) hay escritores, músicos, pintores y escultores que aman la cultura asturiana y se preocupan por Asturias, su lengua y su idiosincrasia, que ven en la industrialización un grave peligro para la región y que añoran ese pasado bucólico de vida pura y campestre, de tradiciones sencillas y gentes bonachonas. Este movimiento político y cultural propio de Asturias se viene denominando 'Regionalismo': la temática asturiana, el interés por la región y la voluntad de diferenciar lo típicamente asturiano son características en común de estos "regionalistas". La lengua es una seña de identidad importante y, por ello, el 10 de febrero de 1919 se crea en Gijón -villa donde se reunían la mayoría de los escritores regionalistas- la "Real Academia Asturiana de Artes y Letras", con la presidencia de honor del Príncipe de Asturias. Ya hemos señalado que Fabricio fue uno de sus principales promotores.

Una publicación importante dentro de este movimiento regionalista fue la antología de Enrique García Rendueles Los nuevos bablistas (1925) ${ }^{4}$. Es precisamente en el archivo de este antólogo donde aparecieron los manuscritos que aquí nos ocupan. $\mathrm{Y}$ decimos que es importante porque se rescatan muchas poesías en

4 Se incluyen poesías de: José Caveda Nava, Juan María Acebal, Teodoro Cuesta, Perfecto Fernández Usatorre (Nolón), Félix Aramburu Zuloaga, José Quevedo, Félix López del Vallado, Bernardo Acebedo Huelves, José Benigno García (Marcos del Torniello), Atanasio Palacio Valdés, Francisco González Prieto (Pachu'l Péritu), Jorge Suárez de la Riera, Juan Menéndez Pidal, Rufino Martínez Vázquez, José García Peláez (Pepín de Pría), José Aniceto González, Ricardo García-Rendueles, Fabriciano González García (Fabricio), Carlos de la Concha, Isidro Díez de la Torre, Daniel Albuerne, Enrique García-Rendueles, Alfredo García Dóriga, Ángel García Peláez (Ángel de la Moria), Amable González Abín, Luis Martínez de la Vega, Ramón García González, Conrado Villar Loza, Mario Gómez y José María Flórez González. 
lengua asturiana que, hasta entonces, no habían tenido una amplia difusión. Además, pretende dar continuidad a la antología de José Caveda Nava (1839) ${ }^{5}$, ampliada y anotada después por Fermín Canella Secades: Poesías selectas en dialecto asturiano (Caveda y Canella, 1887) ${ }^{6}$. Fabricio estaba presente con seis poemas. Lo importante de esta obra es que el antólogo quería reivindicar la literatura asturiana y dignificar la lengua asturiana; una forma de hacerlo era mediante la traducción de las modélicas literaturas clásicas. Contaba con textos latinos, como los dos Beatus ille horacianos en versión de Acebal y de Álvarez Amandi (González Delgado, 2004), pero no disponía de textos de la literatura griega traducidos al asturiano (o los desconocía). Así, tiene que realizar traducciones de dicha literatura para incluirlos en su antología, por lo que ofrece el Himno homérico A la Luna y una selección de Trabajos y Días (42-105) que refiere el mito de Prometeo y Pandora -esta última siguiendo la castellana de Miguel Jiménez Aquino- (González Delgado, 2012, 50-54). Tal vez por eso Fabricio le haría llegar sus traducciones manuscritas, que vamos a ofrecer aquí y que aparecieron en el archivo del antólogo.

Esta práctica de la traducción no es extraña en Fabriciano González. A pesar de su temática netamente costumbrista, como indica Castañón $(1987,21)$, "se conocen versiones que hizo al bable de composiciones de Heine, Campoamor, Curros Enríquez, Villaespesa y Teócrito". En su antología aparece una muestra de todos ellos, salvo de Heine, y sumamos el poema latino "Stabat

5 Esta antología fue el primer libro publicado con textos en lengua asturiana (desde el siglo XVII en adelante, firmados por Antonio González Reguera, Francisco Bernaldo de Quirós, Antonio Balvidares, Bruno Fernández Cepeda, Josefa Jovellanos y otros "de autores desconocidos" -entre los que se encuentran los del antólogo-). La obra servirá como modelo para futuros escritores en lengua asturiana.

6 Completa la antología anterior con poemas anónimos y un bloque de "autores modernos" entre quienes se encuentran: Ramón García Alas, Fr. Domingo Hevia Prieto, Benito Canella Meana, José Napoleón Acebal Morán, Higinio del Campo Cañaveras, Juan Francisco Fernández Flórez, Teodoro Cuesta, Plácido de Jove y Hevia, Marcelino Flórez de Prado, José María Flórez González, Justo Álvarez Amandi, Félix Aramburu Zuloaga, Ángel Peláez y otros autores citados de los que no reproduce textos literarios. 
mater speciosa", del franciscano Fray Jacobo Benedetti. Precisamente el de Teócrito es el último que aparece en la recopilación de Castañón y sospechamos que debió de aparecer en un manuscrito al que pudo tener acceso el editor, pues aparece fechado (como el antepenúltimo) y los tres últimos poemas no siguen el orden alfabético por título que, parece, es la premisa que se sigue en la disposición de los poemas que no pertenecen a Munchu güeyu. Hasta ahora, era el único poema de temática helénica que se conocía de Fabricio, y por ello, antes de pasar a comentar los otros dos que han aparecido manuscritos y que se presentan aquí por vez primera, conviene que nos detengamos en él: "El ladronzuelo de panales".

\section{3. "El ladronzuelo de panales"}

El idilio XIX de Teócrito es uno de los más conocidos del autor y tuvo una especial recepción en la literatura occidental7: Eros se queja ante su madre de la picadura de una abeja y Afrodita compara a su hijo con el animal, sirviéndose del tamaño y del daño que provoca. Sin embargo, se pone en duda la autoría teocritea, pues no aparece en los más importantes y antiguos manuscritos de poesía bucólica ${ }^{8}$. Algunos filólogos lo atribuyen a Mosco, a Bión $\mathrm{o}$, incluso, a poetas posteriores [por su semejanza con poemas anacreónticos, como el XXXV (Brioso), de filiación epigramáticaํ].

7 No en vano, fue uno de los primeros idilios de Teócrito traducidos al vasco (por José Manterola) y publicado en revistas de la época (González Delgado, 2005, 378-379). Es importante señalar que, desde el siglo XVI, este poema contó con varias traducciones neolatinas -Strozzi, Hesse, Scaliger, Alciato, Vel, Melanchthon, Camerario, Moltzer, Capilupi, Estienne, Mariner, Herrera Temiño, etc. (Ruiz Sánchez y Castro de Castro, 2000)- y con una amplia recepción en las literaturas románicas (González Palencia y Mele, 1949). Fue también traducido al latín y al castellano por Cándido M.․ Trigueros (Nieto Ibáñez, 2008).

8 No es fácil separar lo escrito verdaderamente por Teócrito de su obra apócrifa, que fue con el tiempo mezclándose con su poesía original. Véanse Martínez Fernández (1975) y García Teijeiro y Molinos Tejada (1986, 32-37).

9 José Villalaín Fernández, que utiliza el pseudónimo L'Americanín de Romadorio, tradujo al asturiano esta anacreóntica, bajo el título "El amor. Paráfrasis de Anacreonte" y que apareció en un manuscrito en el archivo de García Oliveros fe- 
Castañón lo incluye en su antología (Fabricio, 1987, 189), precisamente en último lugar, dando la sensación de que lo toma de un manuscrito, pues no sigue el orden alfabético que parecen seguir los demás poemas y también, a diferencia de las anteriores, aparece datado: 1927. El poema se antoja como una especie de traducción que presenta muchas ampliaciones (los ocho hexámetros del original se convierten en catorce versos: un soneto formado por dos cuartetos y dos tercetos encadenados). Sin embargo, no rompe la unidad del poema en ese deseo de querer adaptar los versos griegos a la estructura del soneto. Veamos los textos enfrentados:

\begin{tabular}{|c|c|c|}
\hline $\begin{array}{l}\text { Pica una abeya al travesau Cupidu } \\
\text { porque i furtia la miel del so caxellu, } \\
\text { glaya el neñu, solluta sin consuellu }\end{array}$ & & 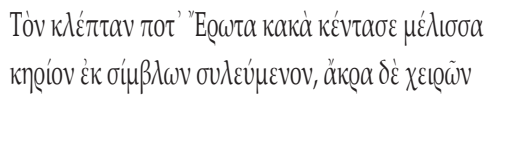 \\
\hline $\begin{array}{l}\text { Yasóplase n'el deu dolloridu; } \\
\text { berrayespatuxando condollidu }\end{array}$ & 5 & 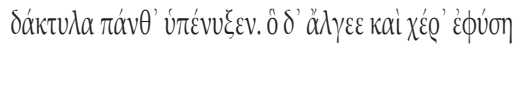 \\
\hline $\begin{array}{l}\text { va'currucase de so má n'el cuellu: } \\
\text {-Teno pupa, mamina, diz el perbellu, } \\
\text { iy qué animal tan ruin me punxo tuidu! }\end{array}$ & & 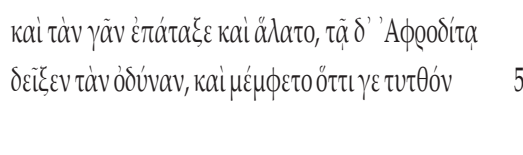 \\
\hline $\begin{array}{l}\text {-No empapielles, mio amor. ¿Non te asemeyes } \\
\text { (dixoiCíteresconfisgá sunrisa) }\end{array}$ & 10 & 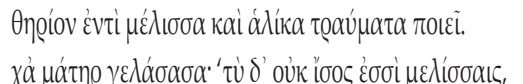 \\
\hline $\begin{array}{l}\text { tú tamién a les pérfides abeyes? } \\
\text { Menuducu como elles faes la guisa, }\end{array}$ & & \\
\hline $\begin{array}{l}\text { Y les llagues que das a los que tueyes } \\
\text { jmalamám si españar los faen de risa! }\end{array}$ & & 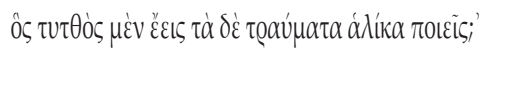 \\
\hline
\end{tabular}

chado el 31 de marzo de 1938. Se publicó en 1997 y podemos leerlo en González Delgado (2008, 69-70 y 2012, 57-58): “Aloriáu como siempre I taba'nte roses Eros, I cuando una abeya gafa I llantói todo'l oblero, I poniendoi una nalga [5] I bermeya como'l fuéu. I Berrando, paticando, I y acoxando y corriendo, I foi col cuento a so má I (a la siñora Venus) [10] | clamiando'stoy muy malo, | toy per detrás enceso, | porque mordéume un cuélebre | y metiome veneno | o gafez n'una ñalga. [15] | - ¿Un cuélebre mió neño? I -Un cuélebre con ales, I si siñora, uno d'esos I que pa los llabradores I fain miel e'nos caxellos. [20] I - ¿Y quéxeste rapaz, I y estaferies por eso? I ¡Entós qui non fairán, I que non dirán aquellos I que tu con les tus fleches [25] | faislos vivir morriendo I como non tengan l'ánima | y el corazón de fierro?". 
Así, los versos sexto, séptimo y los dos últimos, además de la mitad del tercero (insisten en el dolor, $\alpha \ddot{\lambda} \lambda \gamma \varepsilon \varepsilon$ del original) y del noveno (las primeras palabras de consuelo de su madre), son ampliaciones por interpretación del autor, del mismo modo que el diálogo (en el texto griego solo Afrodita toma la palabra). Por otro lado, en el original aparece en el primer verso $\kappa \alpha \kappa \alpha \dot{\alpha} \mu \varepsilon ́ \lambda \iota \sigma \sigma \alpha$ ("malvada abeja") y el autor prefiere dejar el adjetivo para el final de la composición ("pérfides", v. 11). El resto se ajusta al original.

Fabriciano González ya había citado a finales de 1926, en tres artículos periodísticos ${ }^{10}$ a propósito del no reconocimiento oficial del asturiano como lengua regional, según el Real Decreto de 26 de noviembre de 1926, unas versiones asturianas de los bucólicos:

Pero ¿se acomoda bien el bable asturiano a todos los estilos y modalidades literarias? Desde luego. Basta para convencerse de ello el hecho de que, aparte los escritos originales de reconocido mérito que en él existen, hay también traducciones diversas que no desmerecen de aquellos: como la del Evangelio de San Mateo, editado en Londres; las de algunos idilios y odas de los clásicos griegos y latinos (Teócrito, Bión, Mosco y Horacio) y las versiones igualmente estimables de diferentes poesías castellanas, catalanas y gallegas, que a nuestro juicio conservan el mismo vigor y la misma fuerza expresiva que en los modelos.

Junto a las conocidas traducciones del obispo Manuel Fernández de Castro para el proyecto del príncipe Luis Luciano Bonaparte para traducir La Biblia a diversas lenguas (en Londres, en 1861) o las versiones de Horacio de Acebal y Amandi (González Delgado, 2004), cita odas griegas de Teócrito, Bión y Mosco al asturiano que, hasta donde sabemos, no estaban publicadas. Al año siguiente, fecha él su versión, por lo que las traducciones

10 Los tres artículos son "Afirmación del bable" (1-XII-1926), "Insistiendo en la afirmación del bable" (7-XII-1926) y "En defensa del bable" (18-XII-1926). La cita se toma del segundo de ellos. 
que refiere tienen que ser de otro autor. Efectivamente, parece que conocía las versiones de Félix Aramburu y Zuloaga que permanecieron inéditas hasta 1985 (Fernández Buelta, 1985; González Delgado, 2010-2011; 2015) ${ }^{11}$. No sólo las conocía, sino que se apropia de ellas, pues su versión es prácticamente igual que la de Aramburu (señalamos en cursiva los términos que cambia):

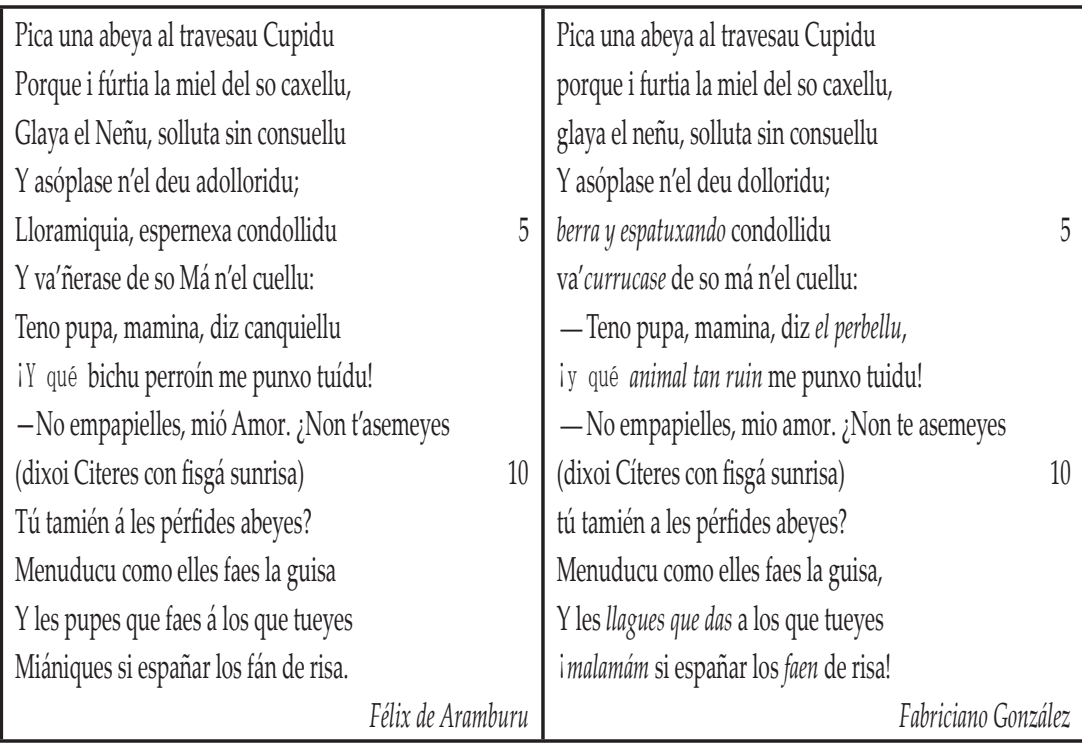

11 Félix Aramburu Zuloaga (1848-1913), catedrático de Derecho y Rector de la Universidad de Oviedo, dejó inédita una "Traducción al bable de poesías bucólicas griegas". Estas poesías fueron conocidas a través de la fotocopia del manuscrito a mediados de los ochenta del siglo pasado (Fernández Buelta, 1985) publicada en una revista que escapaba de las publicaciones convencionales de poesía asturiana, pero gracias a la cita que de ellas hizo Piñán (1993), González Delgado (2010-2011) las recuperó y analizó, situándolas a comienzos del siglo XX y adscribiéndolas correctamente: aunque el escritor atribuyó los tres idilios a Teócrito (XXVIII, XIX y IX: “La rueca”, “El ladronzuelo de panales" y "Bión”), según las ediciones modernas los dos primeros estarían correctamente adscritos, pero el tercero se correspondería con el fragmento 14 de Bión. También señalaba que estas traducciones de algún modo circularon manuscritas en círculos culturales, aunque no aparecen recogidas en la antología de García Rendueles (1925), pero que sí las conocía Fabriciano González, que reelabora una en 1927 y que podemos leer en Fabricio $(1987,189)$. 
Fabricio toma el texto de Aramburu (tuvo acceso a su archivo o conoció el poema por alguien del círculo íntimo) y hace pequeños cambios sirviéndose de sinónimos: berra / lloramiquia, espatuxando / espernexa, acurrucase / añerase, animal tan ruin / bichu perroín, llagues que das / pupes que faes, malamán / miániques. Si nos pareció de gran acierto por parte de Aramburu el término esper-

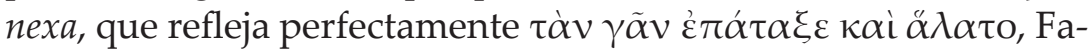
bricio prefiere un espatuxando que nos gusta más.

Si Fabricio toma el texto de Aramburu, éste tenía a mano la traducción castellana de Ignacio Montes de Oca (1914, 163-164), publicada primero en México en 1877 y luego en Madrid, en la "Biblioteca Clásica", en 1880 y varias veces reeditada (González González y González Delgado, 2005, 195-198). Además de la adaptación del poema a un soneto, se ve claramente el origen de las innovaciones que hemos señalado (especialmente en la segunda parte de la composición) y, tal vez por eso, Aramburu no quiso que sus versiones vieran la luz y circulasen en copias manuscritas:

\begin{tabular}{|c|c|}
\hline Punza una abeja a Amor, que sin recelo & Pica una abeya al travesau Cupidu \\
\hline Roba procaz la miel de los panales. & Porque i fúrtia la miel del so caxellu, \\
\hline Grita Cupido, y quiere de sus males & Glaya el Neñu, solluta sin consuellu \\
\hline Soplándose la mano hallar consuelo. & Y asóplase n'el deu adolloridu; \\
\hline Salta; y batiendo con los pies el suelo & Lloramiquia, espernexa condollidu \\
\hline Refúgiase en los brazos maternales, & Y va'ñerase de so Má n'el cuellu: \\
\hline Diciendo: "Ve qué llagas tan fatales & Teno pupa, mamina, diz canquiellu \\
\hline Deja un animalillo pequeñuelo." & iY qué bichu perroín me punxo tuídu! \\
\hline "Por qué lloras, mi Amor? No te asemejas & - No empapielles, mió Amor. ¿Non t'asemeyes \\
\hline (Con risa celestial clama Citeres) & (dixoi Citeres con fisgá sunrisa) \\
\hline Tú también a las pérfidas abejas? & Tú tamién á les pérfides abeyes? \\
\hline Pequeñuelo ¡oh rapaz! cual ellas eres; & Menuducu como elles faes la guisa \\
\hline Pero ¡qué llagas tan fatales dejas & Y les pupes que faes á los que tueyes \\
\hline Con tu temido arpón siempre que hieres!". & Miániques si españar los fán de risa. \\
\hline Ignacio Montes de Oca & Félix de Aramburu \\
\hline
\end{tabular}


Los autores asturianos mantienen el mismo título, aunque omiten el argumento y las notas que incluye el obispo mexicano. Aramburu toma la traducción de Montes de Oca poniéndola en asturiano y Fabricio plagia la de Aramburu.

\section{4. "A la muerte de Adonis"}

Bajo la signatura Ast mss G.R. C 7-3, está depositado en la Biblioteca de Asturias este manuscrito, de papel muy fino y transparente, en tres hojas, de $21 \times 16 \mathrm{~cm}$, numeradas en la parte superior derecha, y escritas únicamente por el recto, que lleva por título "A la muerte de Adonis (Versión al bable del Idilio XXX de Teócrito)". Está fechado al final en "Gijón 1926", fecha que, por otro lado, está próxima a la del idilio anterior y, también, a los artículos periodísticos en que citaba traducciones de los bucólicos griegos. Transcribimos a continuación dicho Idilio con el texto original al frente. Aunque en el subtítulo dice que es versión bable del XXX de Teócrito, se trata de un texto anónimo que figuró en el corpus Theocriteum y que lleva por título "Eiऽ vekoòv 'A $\delta \omega v \iota v "$ y que aparece al final de las ediciones críticas de los poetas bucólicos griegos (Gow, 1952, 166-167) ${ }^{12}$.

12 Tan solo un manuscrito (codex Vaticanus 1824, del siglo XV) lo atribuye a Teócrito. El poema ya se conoce desde la edición Aldina (1495) y bajo el número XXX aparece en el corpus Theocriteum en varias ediciones, como la de Stephanus. Beckby lo considera apócrifo, pero lo incluye en Teócrito bajo el número XXXIII. Gow lo recoge como texto anónimo al final de su edición crítica. En las traducciones castellanas de líricos griegos que incluían a Teócrito con anterioridad a nuestras versiones, Conde no traduce esta composición en su antología publicada en 1796 al no considerarla pastoril; sí traduce "El robador de panales" (bajo el número XV) y "La rueca" (XXI); Montes de Oca, por su parte, traduce los tres poemas, con dos versiones de éste (González González y González Delgado, 2005). 
A la Muerte de Adonis

(Versión al bable del Idilio XXX de Teócrito)

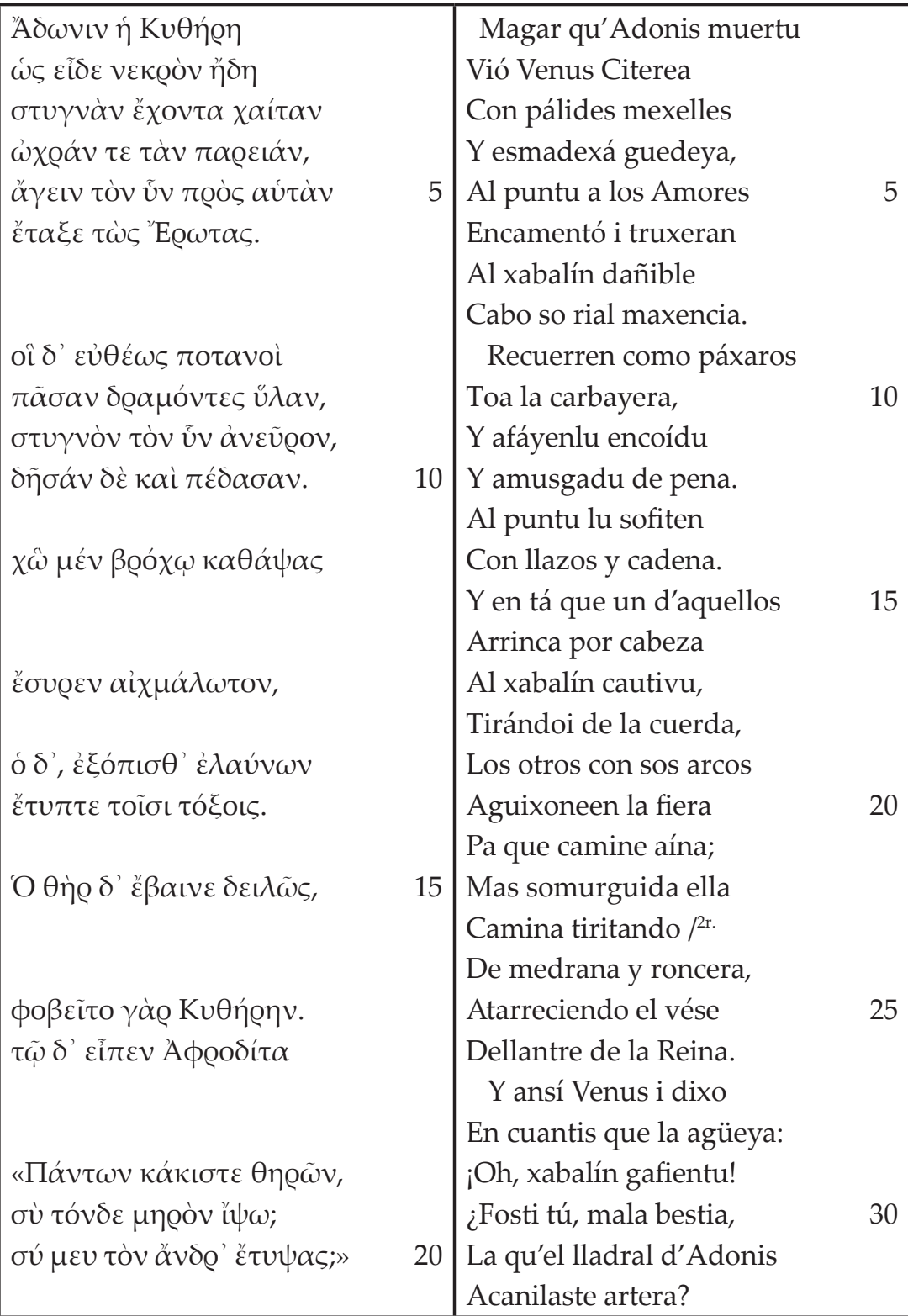




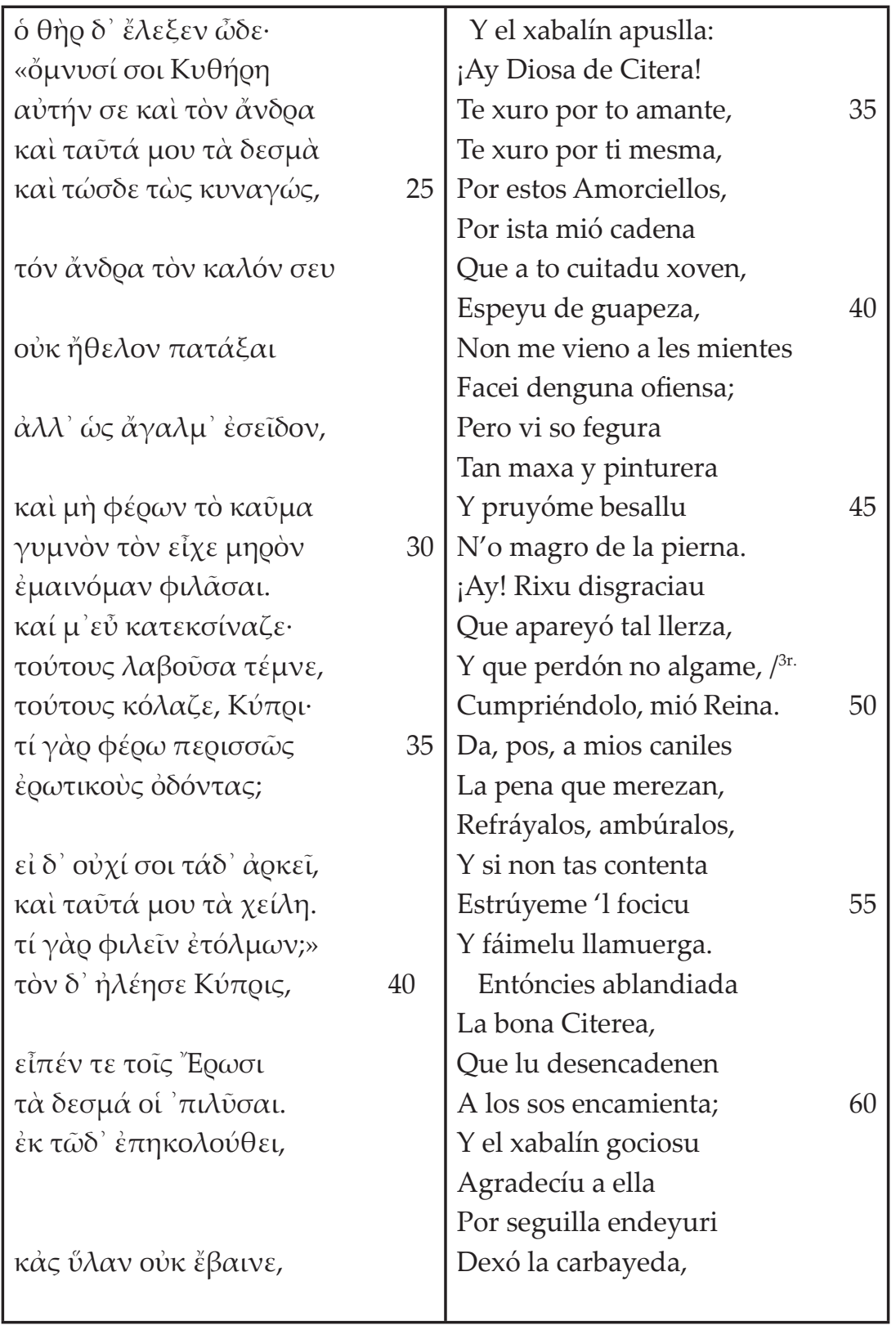




\begin{tabular}{|c|c|}
\hline 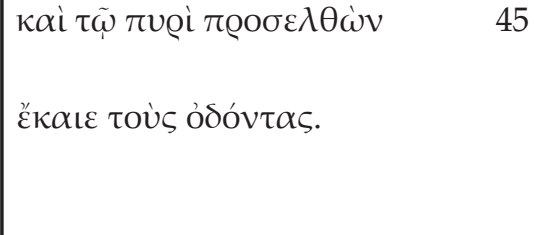 & $\begin{array}{l}\text { Y entenrecíu llugóse } \\
\text { Cabo una gran foguera } \\
\text { Y amburó los caniles } \\
\text { Que tantu mal fixeran. } \\
\text { Gijón } 1926 \\
\text { Fabricio }\end{array}$ \\
\hline
\end{tabular}

El tema de este poema, fechado a finales de época imperial o comienzos de la bizantina (Wilamowitz, Beckby, Legrand), está relacionado con el "Canto fúnebre por Adonis" de Bión ${ }^{13}$ : Afrodita ordena a sus Amorcillos capturar al jabalí que provocó la herida mortal a su querido Adonis y, ante la diosa, la fiera se justifica, señalando que lo hirió por amor y sin querer. Afrodita lo perdona y él la sigue y se autocastiga. El estilo de este poema es similar al anterior y su tono recuerda el de las Anacreónticas; incluso también su métrica: los 46 dímetros yámbicos catalépticos se corresponden muy bien con la versión asturiana (heptasílabos con rima asonante en los pares) al ser ambos versos heptasílabos. Sin embargo, el asturiano emplea 68 versos (un $48 \%$ más) debido a las ampliaciones y recreaciones (incidiendo en los sentimientos del animal) que lleva a cabo y que se ven bien en la confrontación de los textos que hemos realizado. Así, por ejemplo, en los primeros versos "Venus" (v. 2), "rial maxencia" (v. 8) no aparecen en el original. Tampoco "Al puntu" (v. 5), que anticipa عủ $\theta \dot{\varepsilon} \omega \varsigma$ (v. 7) y que vuelve a traducir más adelante (v. 10), al igual que

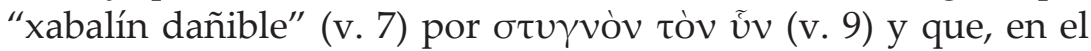
lugar que le tocaba, incide en el miedo y la tristeza del animal ("encoídu / y amusgadu de pena" (vv. 11-12; también en los vv. 24-26, 61-62, 65, claras ampliaciones de los sentimientos del animal). Transforma el bosque (úd $\alpha v$, vv. 8 y 44) en "carbayera"

13 Este poeta, oriundo de la zona de Esmirna, fue el tercero y último de los bucólicos griegos (tras Teócrito y Mosco) y vivió entre los siglos II-I a.C. Conocemos datos a través del "Canto fúnebre por Bión" de Mosco (III). En el género, Bión pierde el sentimiento por el paisaje a favor de incrementar el interés por las cuitas amorosas. 
(v. 10) y "carbayeda" (v. 64), intentando dar al poema un ambiente más asturiano, y convierte en una comparación ("como

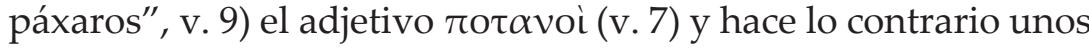
versos más adelante, al verter la comparación $\omega \varsigma$ $\alpha ́ \gamma \alpha \lambda \mu \alpha$ (v. 28) en "so figura / tan maxa y pinturera" (vv. 43-44); desdobla el da-

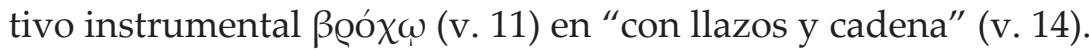
El desdoblamiento también se produce en el vocativo con superlativo del v. 18 del original (véanse vv. 29-30 de la traducción). El nombre de la diosa es tan pronto Venus (teónimo latino de Afrodita) como Citerea (sobrenombre frecuente en las fuentes clásicas, pero más desconocido para lectores populares, por lo que el traductor ya lo explica en el v. 2 al ponerlo junto al nombre divi-

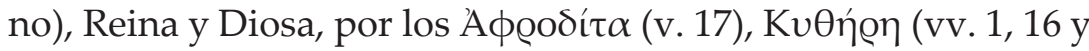
22) y Kúreıs (vv. 34 y 40) del original. Otra de las prácticas que percibimos es la alteración de orden en la traducción de varios elementos. Así, presenta las "mexelles" y la "guedeya" (vv. 3-4), cuando en el original es a la inversa (vv. 3-4), o los juramentos de los vv. 22-25 se trastocan en los vv. 35-38 de la traducción. Respecto a la interpretación del final del poema, el traductor sigue la propuesta de Faber (ỏoóv $\alpha \varsigma$, , v. 46) que hemos mantenido en la presentación del texto griego, pues Gow mantiene el final que presenta el manuscrito ('E $\omega \tau \alpha \varsigma$ ) y que los editores suelen corregir. El traductor recrea esta acción justificándola (v. 68), pues resultaría extraño la quema de los Amorcillos (artificioso recurso metafórico para señalar el castigo de sus pasiones - ̌̌ $\omega \omega \tau \alpha \varsigma-)$. Por lo demás, la traducción realizada es aceptable.

A diferencia del poema anterior y del siguiente, no disponemos de una versión realizada por Aramburu para este poema. Sin embargo, la deuda con la traducción castellana de Montes de Oca no plantea ninguna duda. El obispo mexicano realizó dos versiones de este idilio (Montes de Oca, 1916, 237-239 y 241-243), ambas en versos heptasílabos, pero el autor asturiano prefiere la segunda (con 72 versos, frente a los 60 de la primera), a pesar de señalarse que fue un primer ensayo realizado por el traductor en sus años juveniles: 
Cuando vio a Adonis muerto

La Diosa Citerea

Con pálidas mejillas

Y suelta cabellera,

Mandó a los Amorcillos

Que luego condujeran

Al jabalí asesino

A su real presencia.

Veloces recorrieron

Cual pájaros la selva,

Y lleno lo encontraron

De duelo y de tristeza.

Atáronlo al instante

Con lazos y cadenas.

Y mientras uno de ellos

Marchaba a la cabeza

Al jabalí cautivo

Tirando de la cuerda,

Los otros con sus arcos

Herían a la fiera

Para que a su destino

Llegara con presteza;

Mas ella caminaba

Silenciosa y lenta

Temiendo los enojos

De la Ciprina Reina.

Y así le dijo Venus

Cuando venir lo viera:

“¡Oh tú de cuantas viven

La más osada bestia!

¿Tú laceraste, díme,

Aquella forma bella?

¿Tú eres quien a mi Adonis

Ha dado muerte acerba?"

Y el jabalí responde:
Magar qu'Adonis muertu

Vió Venus Citerea

Con pálides mexelles

Y esmadexá guedeya,

5 Al puntu a los Amores

Encamentó i truxeran

Al xabalín dañible

Cabo so rial maxencia.

Recuerren como páxaros

10 Toa la carbayera,

Y afáyenlu encoídu

Y amusgadu de pena.

Al puntu lu sofiten

Con llazos y cadena.

Y en tá que un d'aquellos

Arrinca por cabeza

Al xabalín cautivu,

Tirándoi de la cuerda,

Los otros con sos arcos

20

Aguixoneen la fiera

Pa que camine aína;

Mas somurguida ella

Camina tiritando $/ 2$ r.

De medrana y roncera,

Atarreciendo el vése

Dellantre de la Reina.

Y ansí Venus i dixo

En cuantis que la agüeya:

¡Oh, xabalín gafientu!

¿Fosti tú, mala bestia,

La qu'el lladral d'Adonis

Acanilaste artera?

Y el xabalín apuslla: 
“Oh Diosa de Citera!

Te juro por tu amante,

Te juro por ti mesma,

Por estos cazadores,

Por estas mis cadenas,

Que a tu adorado joven

De célica belleza

Jamás mi intento ha sido

Dañar ni hacer ofensa;

Mas viendo su figura

Cual la de un dios esbelto.

Ya resistir no supe

De mi pasión la fuerza,

$Y$ un beso darle quise

En mi fatal demencia;

Ósculo que produjo

Tan graves consecuencias.

Mas tuyos son mis dientes:

Acéptalos, joh Reina!

$Y$ dales a tu agrado

La pena que merezcan:

$Y$ si esto tu venganza

No deja satisfecha,

Hé aquí también mis labios;

También ellos perezcan."

A compasión se mueve

La Diosa de Citera,

Y manda que al momento

Desaten las cadenas.

Mas por seguir a Venus

La agradecida fiera

Ya desde aquel instante

Jamás tornó a la selva;

Y se llegó contrita

\section{¡Ay Diosa de Citera!}

Te xuro por to amante,

Te xuro por ti mesma,

Por estos Amorciellos,

Por ista mió cadena

Que a to cuitadu xoven,

Espeyu de guapeza,

Non me vieno a les mientes

Facei denguna ofiensa;

Pero vi so fegura

Tan maxa y pinturera

Y pruyóme besallu

o magro de la pierna.

¡Ay! Rixu disgraciau

Que apareyó tal llerza,

Y que perdón no algame, $\beta^{3 r}$.

Cumpriéndolo, mió Reina.

$\mathrm{Da}$, pos, a mios caniles

La pena que merezan,

Refráyalos, ambúralos,

Y si non tas contenta

Estrúyeme ' 1 focicu

60

Y fáimelu llamuerga.

Entóncies ablandiada

La bona Citerea,

Que lu desencadenen

A los sos encamienta;

65

Y el xabalín gociosu

Agradecíu a ella

Por seguilla endeyuri

Dexó la carbayeda,

Y entenrecíu llugóse 


\begin{tabular}{|lr|l|}
\hline $\begin{array}{l}\text { A una flamante hoguera } \\
\text { Quemando los colmillos } \\
\text { Que tanto mal hicieran. }\end{array}$ & & $\begin{array}{l}\text { Cabo una gran foguera } \\
\text { Y amburó los caniles } \\
\text { Ignacio Montes de Oca }\end{array}$ \\
$\begin{aligned} \text { Que tantu mal fixeran. } \\
\text { Fabriciano González }\end{aligned}$ \\
\hline
\end{tabular}

Sin embargo, algunos elementos están tomados de la primera versión como, por ejemplo, cuando Montes de Oca traduce "¿Conque este muslo hermoso I tú laceraste ruda?", esa parte del cuerpo se corresponde con el "lladral" (v. 31) y "la pierna" (v. 46) que señala el asturiano.

\section{5. "La Rueca"}

Vamos a presentar ahora el poema del otro manuscrito hallado en el archivo de García Rendueles: "La Rueca (sobre motivos del Idilio XXVIII de Teócrito)". En este caso el manuscrito, bajo la signatura Ast mss G.R. C 7-4, está escrito en una sola hoja de $21 \times 13 \mathrm{~cm}$, pero por ambas caras -en el recto, se presenta el texto en dos columnas y en el verso, a una-, y no aparece fechado. Por la fecha de los anteriores poemas que recrean los idilios griegos, se podría datar en esos años de 1926-1927. En este caso, es significativo el subtítulo, "sobre motivos", lo que nos estaría llevando a una recreación más que a una traducción propiamente dicha. De hecho, hay referencias anacrónicas asturianas dentro del poema, al aparecer la xana, Asturies, Gigia, Xixón, el Cantábricu o Xovino. Vamos a reproducir el texto del manuscrito, enfrentado al griego original.

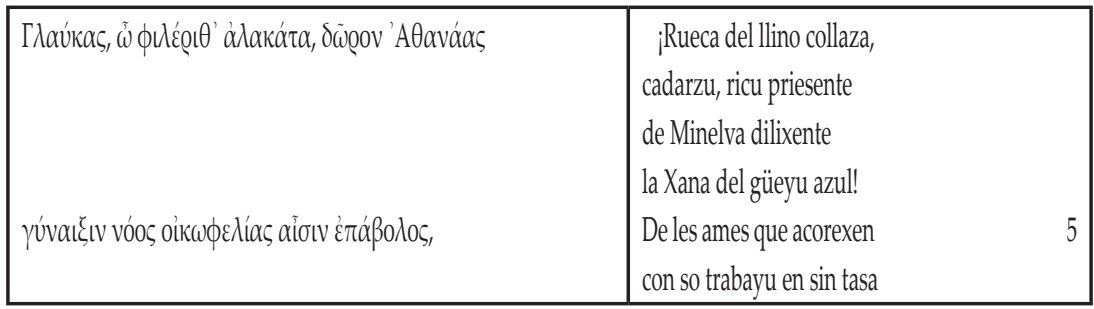




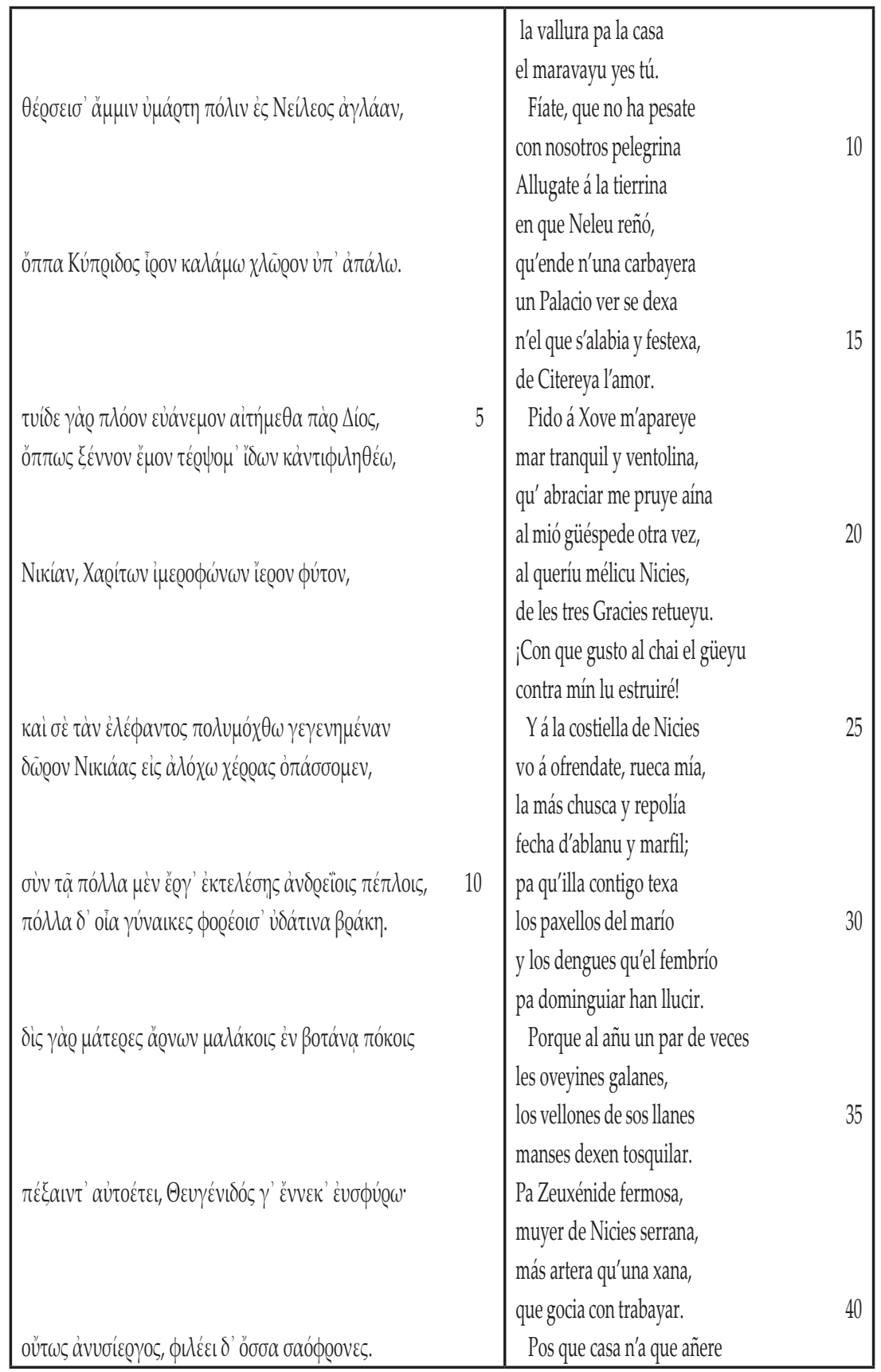




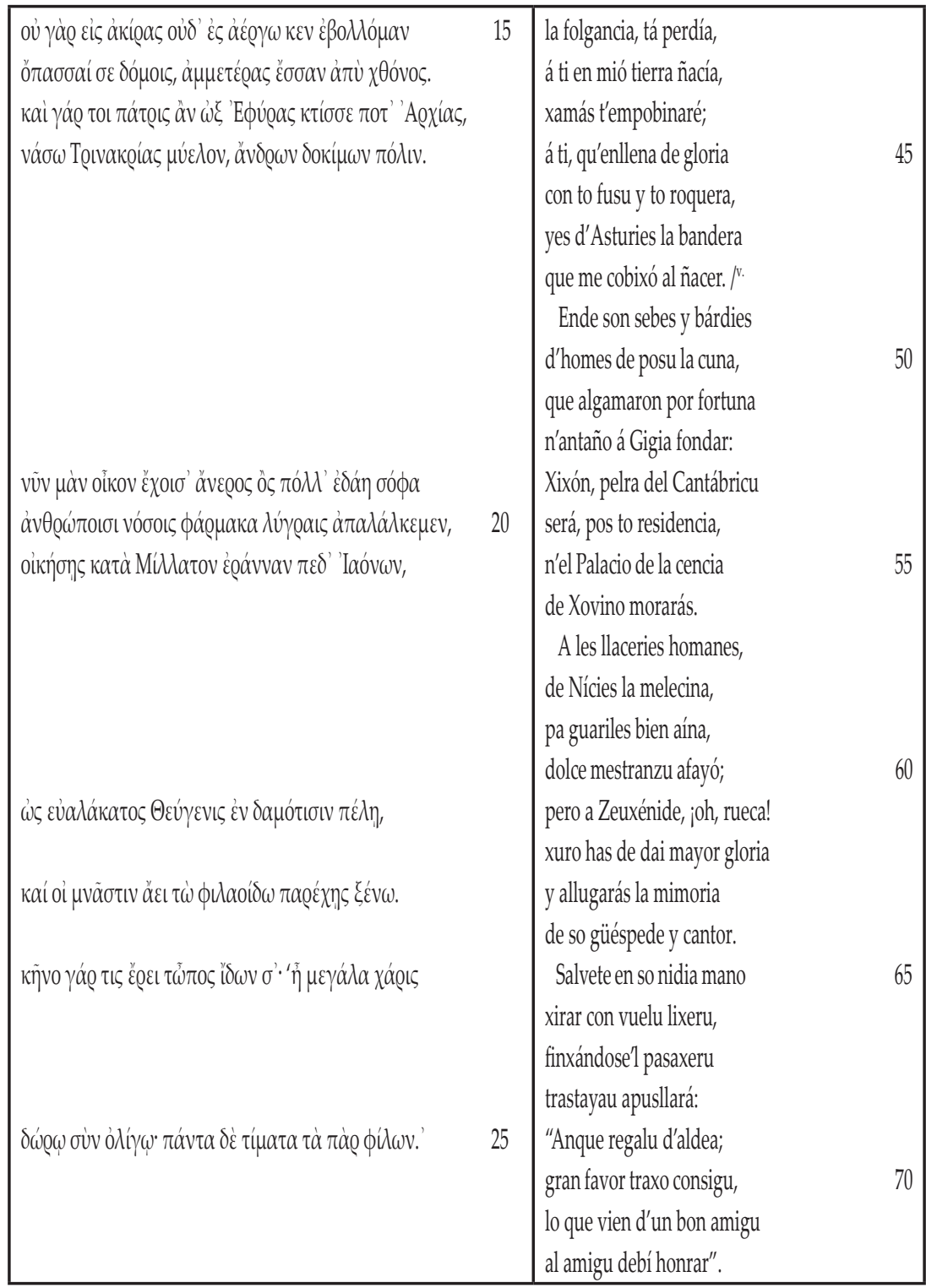


Este idilio XXVIII es un poema anatemático (o de ofrenda) compuesto como acompañamiento de una rueca con la que el médico Nicias obsequia a su esposa Téugenis. Se trataría de una artística y valiosa rueca que Teócrito lleva desde Siracusa a Mileto por petición de su amigo Nicias ${ }^{14}$. Resulta original la perspectiva que adopta el poeta: frente al presente o al pasado, Teócrito recurre al futuro, ya que su virtuosa esposa será también a la luz del regalo, símbolo de los quehaceres femeninos, laboriosa.

Llama la atención que la composición poética escogida no fuese la normal en estos casos: el epigrama ${ }^{15}$. Para un regalo de tal grandeza, el poeta quiso ser original y se decanta por un tono y unos metros más prestigiosos, asentados en la más pura tradición literaria griega, pues recurre al dialecto y al ritmo de los poetas monódicos lesbios (Alceo y Safo) ${ }^{16}$ y consigue un poema de una gran sonoridad (Donnet, 1990). Sin embargo, los veinticinco versos originales de dieciséis sílabas (asclepiadeos mayores) se transforman en nueve estrofas de ocho versos octosílabos con el esquema métrico: - $\mathrm{a} a \mathrm{~b}-\mathrm{c} \mathrm{c}$, donde a y c riman de modo consonante $y \mathrm{~b}$ en asonante aguda. Las significativas ampliaciones que sufre el original se aprecian ya en la primera estrofa (el traductor suele emplear dos versos teocriteos para formar una estrofa y, en total, sobrepasa un $184 \%$ el número de sílabas del texto griego). Muchas ampliaciones se deben al ajuste métri$\mathrm{co}$, añadiendo sobre todo adjetivos y complementos nominales, pero también versos completos (vv. 8, 9, 10, 23-24...). A veces la asturianización del poema contribuye a estas expansiones; anali-

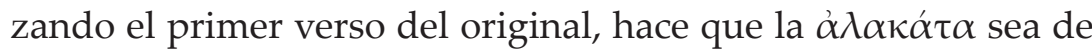
"llino", de manera que se contradice unos versos después, cuan-

14 A este médico van dedicados los idilios XI y XIII de Teócrito y de él habla en el epigrama VIII (AP VI 337), una inscripción para una estatua en cedro de Asclepio que Nicias le dedicó. Véanse comentarios de este idilio en Cairns (1976) o Beligni (2002), que lo interpreta a la luz de los dos versos finales.

15 El libro VI de la Antología Palatina contiene epigramas votivos o de ofrenda.

16 Sobre los idilios eólicos de Teócrito, véase Palutan (1995), que señala, además del metro eólico, homerismos lexicales y morfológicos. También Fassino y Prauscello (2001) analizan la disposición estrófica de dísticos en versos sáficos y alcaicos. 
do refiere los vellones de lana de las ovejas (vv. 34-36); también, cuando cita a la diosa Atenea, el genitivo $\Gamma \lambda \alpha u ́ k \alpha \varsigma$ 'A $\theta \alpha v \alpha ́ \alpha \varsigma$ lo traduce por "de Minelva dilixente / la Xana del güeyu azul". En este sentido, la rueca de marfil está también en la versión asturiana "fecha d'ablanu"; la ropa de hombres y mujeres que preparará Téuxenis ${ }^{17}$ son "paxellos" y "dengues". Algunas adaptaciones

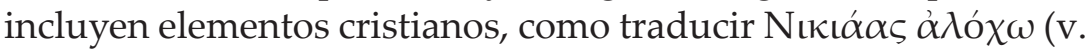
9) por "la costiella de Nicies" (v. 25) para referirse a una Zeuxénide que presenta un nombre mal transcrito (sería Teuxénide o Téuxenis, de la misma manera que llama al autor Teócrito y no Zeócrito; se hace la transcripción del nombre a partir del acusativo, pero la letra zeta inicial debe transcribirse por $\mathrm{T}$ y no por $\mathrm{Z}$ ). Sí creemos más acertada la inclusión del dicho asturiano "regalu

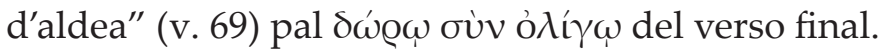

Estas "asturianizaciones", que acercan el poema a los lectores, permiten una mejor comprensión del texto y contribuyen también, en cierta medida, a justificar la falta de anotaciones de la traducción. Por ello, elimina la ubicación helénica por la asturiana: la ciudad de Siracusa, que en el original aparece a través de circunloquios como la patria de su fundador (Arquias de Éfira) o por la isla a la que pertenece (Trinacria, la actual Sicilia), figura cambiada directamente en el texto por Asturias (v. 47), omitiendo de esta manera tanto el nombre de la isla como el de su fundador (señalando en lugar de la región el topónimo de la ciudad natal del autor según su nombre romano: Gigia). También Mileto aparece por primera vez citada en la composición con el nombre que el mito atribuye a su fundador: la ciudad de Neleo (v. 3:

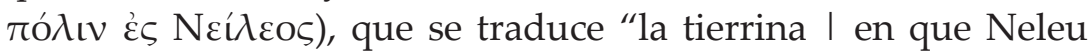
reñó" (vv. 11-12 -llamativa forma del verbo 'reinar'-), aunque después lo hace de forma directa (v. 21), permitiéndose el autor un cambio de ubicación y una extensa recreación: “Xixón, pelra del Cantábricu I será, pos to residencia, I n’el Palacio de la cencia I de Xovino morarás" (vv. 53-56). No sólo vincula el poema

17 Según Pascucci (1967) los versos 10-11 parecen inspirarse en Homero y se explican por Ilíada VI 289. 
a la tierra asturiana, sino que traspone el nombre del fundador de Corinto por el nombre de uno de los asturianos más ilustres: Jovellanos.

Resulta curioso comprobar cómo la traducción deja de respetar el orden original entre los versos 14-21, al producirse una serie de regresiones y anticipaciones que se explican también con las ampliaciones y recreaciones del traductor. La pretendida traducción es, por tanto, muy libre y, al igual que "El ladronzuelo de panales", es un plagio de la traducción que en su día realizó Félix Aramburu, como podemos ver a continuación (marcamos en cursiva las variaciones textuales):

\begin{tabular}{|c|c|c|c|}
\hline Rueca del llino collaza, & & ¡Rueca del llino collaza, & \\
\hline Cadarzín, prenda mañosa & & cadarzu, ricu priesente & \\
\hline De Minelva llaboriosa & & de Minelva dilixente & \\
\hline La Xana del güeyu azul. & & la Xana del güeyu azul! & \\
\hline De les ames que acorexen & 5 & De les ames que acorexen & 5 \\
\hline Con so trabayu sin tasa & & con so trabayu en sin tasa & \\
\hline La vallura pa la casa & & la vallura pa la casa & \\
\hline El maravayu yes tú. & & el maravayu yes tú. & \\
\hline Fíate, que no ha pesate & & Fíate, que no ha pesate & \\
\hline Con nosotros pelegrina & 10 & con nosotros pelegrina & 10 \\
\hline Allugate á la tierrina & & Allugate á la tierrina & \\
\hline N’a que Nelín reñó & & en que Neleu reñó, & \\
\hline Qu'en metá un rebollar, ende & & qu'ende n'una carbayera & \\
\hline Un palacio reverdeya & & un Palacio ver se dexa & \\
\hline N'el que s'allanda á bitreya, & 15 & n'el que s'alabia y festexa, & 15 \\
\hline Palombina del amor. & & de Citereyal' amor. & \\
\hline Pidoá Xove m'apareye & & Pidoá Xove m'apareye & \\
\hline Mar tranquil y ventolina, & & mar tranquil y ventolina, & \\
\hline Que agraciar me pruya aína & & qu' abraciar me pruye aína & \\
\hline Al mió güéspede otra vez, & 20 & al mió güéspede otra vez, & 20 \\
\hline Al queríu mélicu Nicies, & & al queríu mélicu Nicies, & \\
\hline De les tres Gracies retueyu. & & de les tres Gracies retueyu. & \\
\hline ¡Con que gusto al chai el güeyu & & ¡Con que gusto al chai el güeyu & \\
\hline
\end{tabular}




\begin{tabular}{|c|c|c|c|}
\hline \multicolumn{2}{|l|}{ La so mano estruirá! } & \multicolumn{2}{|l|}{ contra mín lu estruiré! } \\
\hline Yá la costiella de Nicies & 25 & Yá la costiella de Nicies & 25 \\
\hline Voá donate, rueca mía, & & vo á ofrendate, rueca mía, & \\
\hline La más chusca y repolía & & la más chusca y repolía & \\
\hline Torniá n'ablanu y marfil; & & fecha d'ablanu y marfil; & \\
\hline Pa qu'illa taza y retasca & & pa qu'illa contigo texa & \\
\hline Los paxellos del marío & 30 & los paxellos del marío & 30 \\
\hline Y los dengues qu'el fembrío & & y los dengues qu'el fembrío & \\
\hline Pa dominguiar han llucir. & & pa dominguiar han llucir. & \\
\hline Porqu' al añu un par de veces & & Porque al añu un par de veces & \\
\hline Les oveyines galanes, & & les oveyines galanes, & \\
\hline De sos vellones les llanes & 35 & los vellones de sos llanes & 35 \\
\hline Manses dexen tosquilar & & manses dexen tosquilar. & \\
\hline Pa Zeuxénide fermosa, & & Pa Zeuxénide fermosa, & \\
\hline Muyer de Nicies serrana, & & muyer de Nicies serrana, & \\
\hline Más artera qu'una xana, & & más artera qu'una xana, & \\
\hline Qu'al trabayu 'stá avezá. & 40 & que gocia con trabayar. & 40 \\
\hline Y por casa n'a que añere & & Pos que casa n'a que añere & \\
\hline La folgancia, tá perdía, & & la folgancia, tá perdía, & \\
\hline Á ti en mió tierra ñacía & & á ti en mió tierra ñacía, & \\
\hline Xamás t'empobinaré; & & xamás t'empobinaré; & \\
\hline Á ti qu'enllena de gloria & 45 & á ti, qu'enllena de gloria & 45 \\
\hline Yes con to fusu y roquera, & & con to fusu y to roquera, & \\
\hline De Siracusa bandera, & & yes d'Asturies la bandera & \\
\hline Que me cobixó al ñacer. & & que me cobixó al ñacer. & \\
\hline Ende son sebes y bárdies & & Ende son sebes y bárdies & \\
\hline D'homes de posu la cuna, & 50 & d'homes de posu la cuna, & 50 \\
\hline Que algamó de la Fortuna & & que algamaron por fortuna & \\
\hline Árquia el Corintiu fondar: & & n'antaño á Gigia fondar: & \\
\hline Miletu, pelra de Xonia, & & Xixón, pelra del Cantábricu & \\
\hline Será pa ti escoyíu ñeru: & & será, pos to residencia, & \\
\hline N'el palacio pintureru & 55 & n'el Palacio de la cencia & 55 \\
\hline De la cencia morarás. & & de Xovino morarás. & \\
\hline Pa guarir nostres llaceries, & & A les llaceries homanes, & \\
\hline Nícies, con so melecina, & & de Nícies la melecina, & \\
\hline
\end{tabular}




\begin{tabular}{|c|c|c|c|}
\hline \multicolumn{2}{|l|}{ Sabiondu y arteru, aína, } & \multicolumn{2}{|l|}{ pa guariles bien aína, } \\
\hline Mil mestranzos afayó; & 60 & dolce mestranzu afayó; & 60 \\
\hline Pero á Zeuxénide jay rueca! & & pero a Zeuxénide, joh, rueca! & \\
\hline Barrunto darás más gloria & & xuro has de dai mayor gloria & \\
\hline Y guardarás la mimoria & & y allugarás la mimoria & \\
\hline De so güéspede y cantor. & & de so güéspede y cantor. & \\
\hline Salvete en so nidia mano & 65 & Salvete en so nidia mano & 65 \\
\hline Xirar con vuelu lixeru, & & xirar con vuelu lixeru, & \\
\hline Finxándose'l pasaxeru & & finxándose'l pasaxeru & \\
\hline Trastayau apusllará: & & trastayau apusllará: & \\
\hline Anque regalu d'aldea; & & "Anque regalu d'aldea; & \\
\hline Apareyó bon provechu, & 70 & gran favor traxo consigu, & 70 \\
\hline Vieno d'amigu correchu & & lo que vien d'un bon amigu & \\
\hline Qu'al amigu quixo honrar. & & al amigu debí honrar". & \\
\hline & Félix de Aramburu & & Fabriciano González \\
\hline
\end{tabular}

En cuanto a la forma, Fabricio respeta el modelo métrico de Aramburu y corrige algunos errores métricos, como por ejemplo la rima asonante de la tercera estrofa, y cambia, a veces con poco acierto, las rimas consonantes de algunos versos (2-3, 14-15, 54-55, 70-71). Respecto al contenido, en unos pocos casos Fabricio intenta ser más fiel al texto. Así, evita circunloquios, por ejemplo, Cipris del v. 4, que Aramburu traduce por "palombina del amor" (v. 16), cuando él prefiere "Citereya". Sin embargo, se aleja del original y de Aramburu al querer vincular el poema con la realidad asturiana circundante, como hemos visto antes, y que Aramburu, al menos, respeta los topónimos originales. Son precisamente en estas recreaciones de Aramburu ("Miletu, perla de Xonia", v. 53) donde se percibe bien que fue Fabricio quien copió la traducción y no al revés (las traducciones de Aramburu, además de una posible datación en fecha anterior, aparecieron sueltas y desubicadas en otro archivo). Intenta, por tanto, como en "El ladronzuelo de panales", mejorar la traducción ya hecha con pequeños cambios, aunque, en este caso, nos parecen menos acertados. 
$\mathrm{Al}$ igual que las composiciones anteriores, la deuda con la traducción castellana de Montes de Oca (1916: 233-236) es innegable (se mantiene el mismo esquema métrico y el mismo número de versos; se omiten, también, el argumento y las notas). Veamos tres estrofas diferentes (vv. 1-8, 33-40 y 49-56):

\begin{tabular}{|l|l|l|}
\hline ¡Rueca del estambre amiga, & Porque dos veces al año & Son tus nativas murallas \\
Rico don, grato presente & Las madres de los corderos & De ínclitos varones cuna, \\
De Minerva diligente, & Su vellón en los oteros & Que concedió la Fortuna \\
La Diosa del ojo azul! & Mansas dejan trasquilar & A Arquias de Efira fundar. \\
De las matronas que aumentan & Para Teugénide bella, & Será la perla de Jonia, \\
Con su trabajo sin tasa & La dama de hermosa planta. & Mileto, tu residencia: \\
Las riquezas de su casa & ¡Tanto el trabajo la encanta, & De un prodigio de la ciencia \\
Las delicias eres tú. & Mujer sabia sin rival! & La morada habitarás. \\
\hline
\end{tabular}

Se percibe cómo de nuevo Aramburu pone en asturiano la versión de Montes de Oca (con alguna edición del original griego a la vista, como se percibe en el caso de Zeuxénide) y Fabricio plagia la de Aramburu, dando un ambiente más asturiano al poema. De las tres composiciones, es la más infiel al texto original. Sin embargo, es llamativo el título. Aramburu mantiene el de Montes de Oca ("La rueca. Idilio XXVIII"), pero Fabricio opta por añadir un "sobre motivos" que da cuenta tanto de la libertad de la traducción con respecto al texto original como de esa insólita ambientación asturiana.

\section{Conclusiones}

A propósito de los manuscritos aquí editados, si comparamos la grafía con la de otros manuscritos del autor, podemos decir que son manuscritos autógrafos de Fabricio. Estos dos poemas helénicos descubiertos, "A la muerte de Adonis" y "La rueca", deben analizarse junto al que ya era conocido del autor desde el año 1987 tras la edición de Luciano Castañón: “El ladronzuelo de panales". No es extraño que estos poemas hayan aparecido en 
el archivo de García Rendueles. El propio Fabricio los enviaría al antólogo por si había nuevas ediciones o ampliaciones de Los nuevos bablistas (poco probable, al no editarse los otros dos volúmenes proyectados que completaban la obra).

Los tres poemas helénicos aquí vistos son idilios atribuidos en su momento a Teócrito, el poeta bucólico natural de Siracusa que vivió en la corte de Alejandría en el siglo III a.C. y que participó de la renovación literaria de la época helenística. Sin embargo, no presentan la temática bucólica esperada. En ningún lugar aparece el escenario campestre, ni sus protagonistas son pastores o vaqueiros; únicamente el punto en común entre ellos es el tema amoroso. En realidad, el término bucólico referido a Teócrito y sus imitadores fue empleado de forma abusiva en la tradición literaria y los poemas que hemos visto no se distinguirían de otros que no entran en tal categoría, pero sí en la del epigrama. El contenido mítico-amoroso de los dos primeros contrasta con el último poema, de ofrenda (aunque el tema amoroso subyace en él). Esta temática no desentona de los poemas amorosos de la literatura asturiana del momento, especialmente por su contexto rural y campestre, a pesar de que, en los dos primeros, aparezcan personajes míticos harto conocidos y, en "La rueca", debido a su temática diferente, es la versión que Fabricio más "asturianiza".

Los textos manuscritos aparecen sin presentación (un breve subtítulo) ni anotaciones de ningún tipo, aunque en este estudio hemos dejado patentes las traducciones que se han utilizado. Se percibe, además, una postura diglósica al presentar en castellano el título de un poema escrito en asturiano. Está claro, en el análisis de las traducciones, la diferencia de criterio a la hora de traducir con respecto a la época actual, en la que predomina la fidelidad al texto. Se entendía la traducción como una reescritura del original. Las abundantes ampliaciones se pueden explicar por la adaptación métrica, por la recreación libre del poeta al emular el texto original e incidir especialmente en las emociones de los personajes y por el deseo de acercar el mundo heleno a la realidad asturiana, "asturianizando" algunos elementos, como 
hemos visto especialmente en "La rueca" y que nos sirve, además, para ver que el autor tenía a mano la versión realizada por Aramburu que era, a su vez, una traducción asturiana de la castellana de Montes de Oca (motivo, probablemente, por el que su autor nunca las publicó). Todos ellos prefieren los teónimos latinos a los originales griegos, algo habitual en la época ${ }^{18}$.

Aramburu traduce un tercer idilio, con forma de soneto, al que denomina Idilio IX y titula "Bión", aunque en realidad es el fragmento XIV (Gow) $)^{19}$ de este bucólico griego menos conocido, que vivió a fines del siglo II a.C. y que conservamos por transmisión indirecta, gracias a Estobeo. También lo toma de Montes de Oca $(1914,273)$. Parece que Fabricio o bien no lo conocía o, al menos, prefiere no adueñarse de él; la razón puede apuntar a que este idilio no era de Teócrito, como él pensaba que era el resto, y por eso cita a Mosco y Bión en su artículo periodístico de 1926. Lo cierto es que no ha aparecido una versión suya de este poema basada en la de Aramburu. La duda que se plantea ahora es si "A la muerte de Adonis" contaría también previamente con una versión perdida de Aramburu, al igual que sucede con las otras dos composiciones. La semejanza de la versión de Fabricio con la de Montes de Oca nos hace pensar en dicha posibilidad y, por lo tanto, en la existencia de una perdida versión del que fuera rector de la Universidad de Oviedo (1888-1905) muy cercana a este texto de Fabricio recientemente descubierto.

18 En este sentido, debemos tener presente las palabras de Ignacio Montes de Oca, que en la carta-prólogo (fechada en México, el 15 de febrero de 1883) de Odas de Píndaro (Madrid, 1909) a Menéndez Pelayo señala: “Apartándome de la opinión y práctica de usted y de muchos alemanes e ingleses, he dado a las divinidades griegas los correspondientes nombres latinos. A mi modo de ver, poco importa que el Zeus, la Hera, el Cronos o el Hermes helénicos, no sean exactamente los mismos que el Júpiter, la Juno, el Saturno o el Mercurio romanos. Estamos acostumbrados a confundirlos; la generalidad de los lectores conoce a los últimos e ignora a los primeros, y el adoptar el método que repruebo traería confusión y disminuiría la belleza de la poesía" (pp. XIII-XIV).

19 Se corresponde con X (Edmonds) y XI (Legrand). Sobre esta traducción, González Delgado (2012, 46-47). 


\section{Referencias bibliográficas}

Beligni, F. (2002) "Osservazioni all'idillio XXVIII di Teocrito", Annali dell'Università di Ferrara. N. S. Sezione VI, Lettere, 3, 93-116.

CaIrns, F. (1976) "The distaff of Theugenis. Theocritus, Idyll 28", Papers of the Liverpool Latin seminar 1976, 293-305.

Castañón, L. (1987) "Biografía” en González, F. "Fabricio", Poesías asturianas, Oviedo, IDEA.

CAmpal, X. Ll. (1997) “La poesía non recuperada de Fabriciano González 'Fabricio': una cala”, Lletres asturianes, 62, 113-117.

Caveda y Nava, J. (1839) Colección de poesías en dialecto asturiano, Oviedo, Impr. Benito González [ed. facsimilar Uviéu, Alvízoras, 1989].

Caveda, J. y Canella Secades, F. (1887) Poesías selectas en dialecto asturiano, Oviedo, Impr. Vicente Brid [ed. facsimilar Uviéu, Academia de la Llingua Asturiana, 1987, 2003²; Valladolid, Maxtor, 2009].

Donnet, D. (1990) “La densité sonore de l'idylle 28 de Théocrite", L'Antiquité clássique, 59, 181-192.

FABRicio [GonzÁLez, F.] (1925) Munchu güeyu con la xente de casa. Un alcalde de montera, Gijón, s./n.

- (1943) Rosina: cuento asturiano, Gijón, Compañía Asturiana de Artes Gráficas.

- (1987) Poesías asturianas, L. Castañón (ed.), Oviedo, Instituto de Estudios Asturianos.

- (1999a) Poesíes sueltes (1899-1932), X. Ll. Campal (ed.), Uviéu, Academia de la Llingua Asturiana.

- (1999b) Munchu güeyu con la xente de casa, M. Rodríguez Cueto (ed.), Xixón, vtp.

- (2001a) Obra manuscrita (1921-1946), P. Fidalgo Pravia (ed.), Uviéu, Academia de la Llingua Asturiana.

- (2001b) Polémiques (1924-1931), Uviéu, Academia de la Llingua Asturiana.

- (dir.) (2001c) El Regionalista Astur: edición facsimilar de los $n^{o s}$ 1 al 14 del peródicu asoleyáu en Xixón en 1919 dirixíu por Fabriciano González, Uviéu, Academia de la Llingua Asturiana. 
- (2003) Asturianaes, Uviéu, Trabe (Maestros del humor, 2).

- (2010) Munchu güeyu con la xente de casa. Un alcalde de montera, Uviéu, Academia de la Llingua Asturiana [ed. facsimilar Fabricio, 1925].

Fassino, M. y Prauscello, L. (2001) "Memoria ritmica e memoria poetica: Saffo e Alceo in Teocrito Idilli 28-30 tra

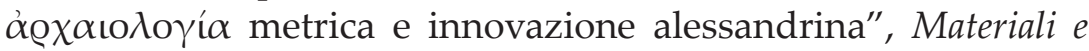
discussioni per l'analisi dei testi classici, 46, 9-37.

Fernández Buelta, J. (1985) “El bable en lo erudito, de Teócrito por Félix Aramburu y Zuloaga", Magister, 3, 89-95.

García, A. (ed.) (1992) El cuentu asturianu (1860-1939), Uviéu, Trabe.

García Rendueles, E. (1925) Los nuevos bablistas. Las mejores poesías en dialecto asturiano de los poetas del siglo XIX, Gijón, Impr. La Reconquista [ed. facsimilar Uviéu, Academia de la Llingua Asturiana, 1987].

García Teijeiro, M. y Molinos Tejada, M. T. (1986) Bucólicos griegos, Madrid, Gredos.

González Delgado, R. (ed.) (2000) Testos en llingua asturiana $n^{\prime}$ El Progreso de Asturias de La Habana. Trescripciones y facsímiles de los nos 1-220 (1919-1925), Uviéu, Academia de la Llingua Asturiana.

- (2004) "Les traducciones d'Horacio al asturianu", Lletres Asturianes, 85, 57-84.

- (2005) "Nacionalismo y regionalismo en la consideración de la literatura grecolatina durante el siglo XIX" en García Jurado, F. (coord.), La historia de la literatura grecolatina en el siglo XIX español: espacio social y literario, Málaga: Universidad (Analecta Malacitana, Anejos 51), 361-383.

- (2008) "La lliteratura grecollatina en llingua asturiana", Lletres Asturianes, 97, 53-102.

- (2010-2011) “Los idilios griegos de Félix Aramburu y Zuloaga", Campo de los patos. Revista asturiana de cultura, 1-2, 357-372.

- (2012) Canta, musa, en lengua asturiana. Estudios de traducción y tradición clásica, Saarbrücken, Editorial Académica Española. 
- (2015) "Primeras traducciones del griego a la lengua asturiana", en Maestre, J. M. et al. (eds.), Humanismo y pervivencia del mundo clásico. V. Homenaje al profesor Juan Gil, Alcañiz-Madrid, Instituto de Estudios Humanísticos-CSIC, II, 1003-1017.

González González, M. y González Delgado, R. (2005) “La lírica griega. Safo, Anacreonte, Tirteo y los bucólicos", en García Jurado, F. (coord.), La historia de la Literatura Grecolatina en el siglo XIX español: espacio social y literario, Málaga: Universidad (Analecta Malacitana, Anejos 51), 181-204.

González Palencia, A. y Mele, E. (1949) “El Amor, ladronzuelo de miel (Divagaciones a propósito de un idilio de Teócrito y de una anacreóntica)", Boletín de la Real Academia Española, 29, $189-228$ y $375-411$.

Gow, A. S. F. (1952) Bucolici graeci, Oxford, E Typ. Clarendoniano.

Martínez Fernández, R. (1975) Los apócrifos de Teócrito en el "Corpus Bucolicorum". La estadística lingüística aplicada al problema de la atribución de autor, Madrid (extracto de Tesis Doctoral, Universidad Complutense).

Montes de Oca y Obregón, I. (1914) Poetas bucólicos griegos traducidos en verso castellano por..., Madrid, Sucesores de Hernando (Biblioteca Clásica, 29 [1880]).

Nieto IbáñEz, J. M. (2008) “La versión del Idilio XIX de Teócrito de Cándido María Trigueros en la tradición bucólica y anacreóntica del XVIII", Cuadernos dieciochistas, 9, 193-210.

Palutan, M. G. (1995) “Osservazioni sui carmi eolici di Teocrito (28, 29 e 30)", Annali dell'Istituto Universitario Orientale di Napoli, Dipartimento di Studi del mondo classico e del Mediterraneo antico, Sezione filologico-letteraria, 17, 89-107.

Pascucci, G. (1967) “Theocr. 28, 10-11”, Maia, 19, 163-168.

Piñán, B. (1993) “La traducción poética al asturianu: del sieglu XIX a Fernán Coronas», en Alcordanza del Padre Galo «Fernán Coronas»", Uviéu, Serviciu de Publicaciones del Principáu d'Asturies, 47-55. 
Ruiz Sánchez, M. y Castro de Castro, J. D. (2000) “El motivo de Cupido y la abeja en la poesía neolatina (I): las traducciones del Idilio XIX de Teócrito", Studia Philologica Valentina, 4, 139-167. 